\title{
Finite element modelling of the mechanical behaviour of unsaturated expansive soils subjected to wetting and drying cycles with shakedown concept
}

\section{Kai Li, Hossein Nowamooz, Cyrille Chazallon \& Bernard Migault}

To cite this article: Kai Li, Hossein Nowamooz, Cyrille Chazallon \& Bernard Migault (2020) Finite element modelling of the mechanical behaviour of unsaturated expansive soils subjected to wetting and drying cycles with shakedown concept, European Journal of Environmental and Civil Engineering, 24:1, 17-33, DOI: 10.1080/19648189.2017.1363666

To link to this article: https://doi.org/10.1080/19648189.2017.1363666

曲 Published online: 07 Sep 2017.

Submit your article to this journal $\pi$

Џ Article views: 100

Q View related articles $\sqsubset$

View Crossmark data \lceil

Citing articles: 3 View citing articles $[7$ 


\title{
Finite element modelling of the mechanical behaviour of unsaturated expansive soils subjected to wetting and drying cycles with shakedown concept
}

\author{
Kai Lia ${ }^{a}, \mathrm{~b}$, Hossein Nowamooz ${ }^{\mathrm{b}}$, Cyrille Chazallon ${ }^{\mathrm{b}, \mathrm{c}}$ and Bernard Migault ${ }^{\mathrm{b}}$ \\ aDepartment of Science, Qingdao University of Technology, Qingdao, China; ' ${ }^{\circ}$ CUBE, UMR 7357, CNRS, INSA de \\ Strasbourg, Université de Strasbourg, 24 Boulevard de la Victoire, 67084, Strasbourg Cedex, France; 'Shandong \\ Provincial Key Laboratory of Road and Traffic Engineering, Shandong Jianzhu University, Jinan, China
}

\begin{abstract}
A simplified model based on the shakedown theory (Zarka method) has been developed in this study for unsaturated expansive soils subjected to wetting and drying cycles. This method determines directly the stabilised limit state. The parameters of the proposed shakedown-based model are calibrated by the suction-controlled odometer tests obtained for an expansive soil compacted at loose and dense initial states, and then validated for the same soil compacted at intermediate initial state by comparing the model predictions with the experimental results. Finally, the finite element equations for the proposed shakedown model are developed and these equations are implemented in the finite element code CAST3M to carry out the fullscale calculations. The performed simulation is on a $2 \mathrm{D}$ geometry, made up of the expansive soil at the intermediate state subjected to successive extremely dry and wet seasons for the different applied vertical loads. The results show the swelling plastic deformations for the lower vertical stresses and the shrinkage deformations for the higher vertical stresses. Only inelastic heaving displacement can be observed in the geometry after considering the residual field.
\end{abstract}

\section{ARTICLE HISTORY}

Received 11 April 2017

Accepted 29 July 2017

\section{KEYWORDS}

Unsaturated expansive soils; Zarka shakedown method; analytical modelling; finite element modelling

\section{Introduction}

Unsaturated expansive soils contain clay minerals such as smectite with the high capacity of water absorption. As the clay minerals absorb water, they expand; conversely, as they lose water, they shrink. The successive wetting and drying cycles produce the differential settlements and crack the structures built on this material (Al-Homoud, Basma, Malkawi, \& Bashabsheh, 1995; Alonso, Romero, Hoffmann, \& Escudero, 2005; Day, 1994; Dif \& Blumel, 1991; Nowamooz and Masrouri 2008; Nowamooz, Jahangir, \& Masrouri, 2013). To investigate the hydro-mechanical behaviour of unsaturated expansive soils, it is necessary to determine the coupled behaviour of expansive soils for the different applied loads and environmental solicitations.

Nowamooz and Masrouri (2010), have performed the tests on loosely and densely compacted bentonite/silt mixtures for several wetting and drying cycles. In their work, the authors pointed out that the loose samples present a shrinkage strain accumulation, while a swelling strain accumulation can be observed for dense samples before reaching a unique equilibrium state at the end of the wetting and 
drying cycles, regardless of the initial dry density of these expansive soil samples. In other words, the loose and dense samples will achieve a unique final state after a number of wetting and drying cycles.

Many methods for volume change prediction of unsaturated expansive soils have been proposed (Alonso, Gens, \& Josa, 1990; Cui, Yahia-Aissa, \& Delage, 2002; Sun, Sheng, Cui, \& Sloan, 2007; Sun \& Sun, 2012; Wheeler, Sharma, \& Buisson, 2003). Barcelona expansive model (BExM) developed by Alonso and co-workers (Alonso, Vaunat, \& Gens, 1999), can be mentioned as the most accepted theoretical reference. This model is able to simulate the basic behaviour of unsaturated expansive soil, including the strain fatigue phenomenon during wetting-drying cycles and the prediction of final equilibrium state at the end of the wetting-drying cycles. However, this model presents a large number of parameters such as the coupling functions for micro- and macrostructural strains. The calibration of these parameters needs several experimental tests which lead to a time-consuming procedure to characterise their hydro-mechanical behaviours.

The classical shakedown theory has been simplified by Zarka (Zarka \& Casier, 1979; Zarka, Frelat, Inglebert, \& Kasmai-Navidi, 1990) for kinematic hardening materials such as metals. Several authors (Allou, Chazallon, \& Hornych, 2007; Chazallon, Allou, et al., 2009; Chazallon, Koval, et al., 2009; Habiballah \& Chazallon, 2005; Sharp \& Booker, 1984) applied this method to study the cyclic mechanical behaviour of soils. They introduced a series of transformed internal variables to characterise the mechanical system and then constructed a local geometry in transformed internal parameter plane to estimate the stabilised limit state and its associated plastic components. This direct determination of the steady solutions in shakedown analysis is able to replace the step-by-step method and needs less model parameters.

In this context, this paper presents a shakedown-based model for the simulation of the volume change problem in expansive soils subjected to several wetting and drying cycles. The constitutive model based on shakedown theory (Zarka method) is firstly presented. The required parameters of this model are next calibrated and validated by the experimental results obtained for an expansive soil compacted at loose, intermediate and dense initial states. After the implementation of the shakedown theory in the finite element code, the plastic strain field and the inelastic displacement field are finally calculated for the 2D geometry, consisted of the intermediately compacted expansive soil and subjected to successive wetting and drying cycles.

\section{Analytical modelling of expansive soils based on shakedown concept}

The purpose of this section is to present a shakedown model based on Zarka method, to simulate the hydro-mechanical behaviour of unsaturated expansive soils during the successive wetting and drying cycles.

\subsection{A simplified yield surface for shakedown modelling}

To describe the hydro-mechanical behaviour of unsaturated soils, it is generally accepted that two independent variables are sufficient:

- For the mechanical behaviour, the term $\left(\sigma_{m}-u_{a}\right)$ is named as the net mean stress $p$;

- For the hydraulic behaviour, the term $\left(u_{a}-u_{w}\right)$ is denoted as the suction term $s$.

where $\sigma_{m}$ is the mean stress and $u_{a^{\prime}} u_{w}$ are the air and water pressures, respectively.

In this section, the net mean stress was taken equal to the applied vertical pressure because of 1D loading. Figure 1 shows a rectangular yield surface in this plane representing the elastic domain. The equations of the different boundaries can be given by:

$$
\begin{aligned}
& s=s_{1} \\
& s=s_{D}
\end{aligned}
$$




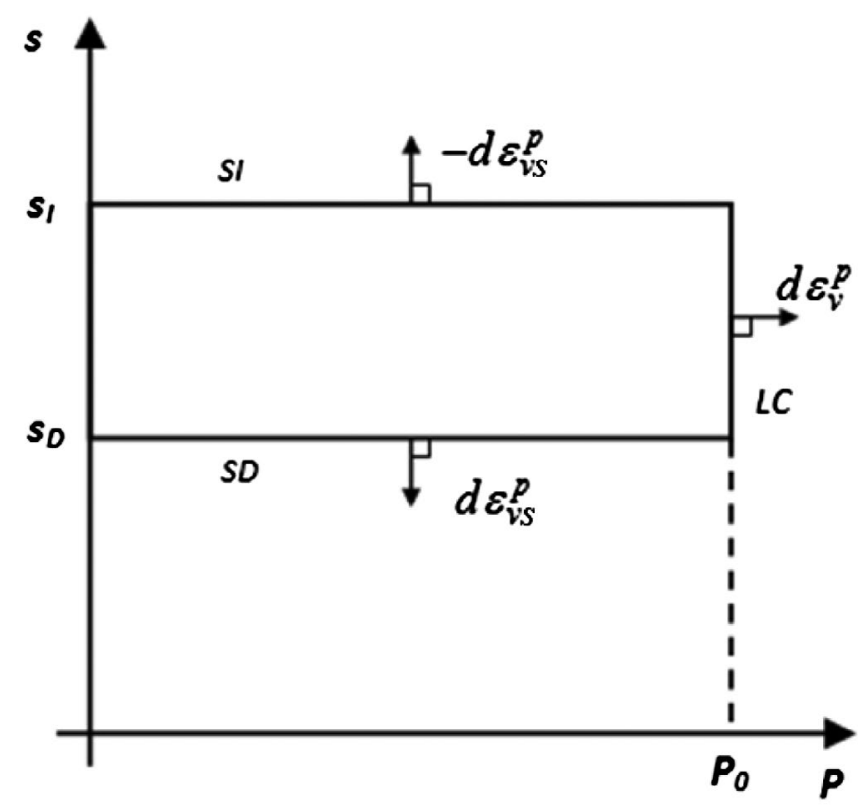

Figure 1. Rectangular shape for the yield surfaces in (suction-preconsolidation stress) plane.

$$
p=p_{0}
$$

where $s$, is the suction increase limit, $s_{D}$ is the suction decrease limit and $p_{0}$ is the preconsolidation stress.

In terms of hydro-mechanical behaviour during wetting and drying cycles, the elastic deformation during cycles is very small, compared with the plastic deformation. Therefore, we take into account that the width of the yield surfaces is small, not changing with suction cycles for the sake of simplicity. On the other hand, the length of the yield surface depends on the suction level, determined by the loading collapse curve. These hypotheses agree with models, such as, BExM model. Although the above simplified model for isotropic stress state has a similar formulation as BExM model, it is only used to the subsequent shakedown modelling, instead of step-by-step calculation of material deformation. To facilitate the shakedown modelling, a rectangular shape of yield surface is employed in this study and it will be employed in the following section of shakedown modelling.

\subsection{Plastic shakedown during suction cycles}

There is an evident hysteresis for expansive soil before suction cycles and this hysteresis becomes smaller with the following suction cycles in Figure 2 (Sharma, 1998; Wheeler et al., 2003). However, it cannot be completely eliminated even though the equilibrium state with no further accumulation of permanent deformation is reached after several suction cycles. Consequently, the plastic shakedown can be used to model the complicated hydro-mechanical behaviour of expansive soils during the wetting and drying cycles.

The proposed yield surface with a kinematic hardening for suction variations can be written as follows:

$$
f=\left|s-y_{\alpha}\right|-s_{\alpha}
$$

where $s_{a}$ is the threshold value of elastic limit for suction variation and $f$ is the yield function, representing the yield surface for suction variation.

The kinematic hardening variable $y_{a}$ can be related to the plastic strain, 


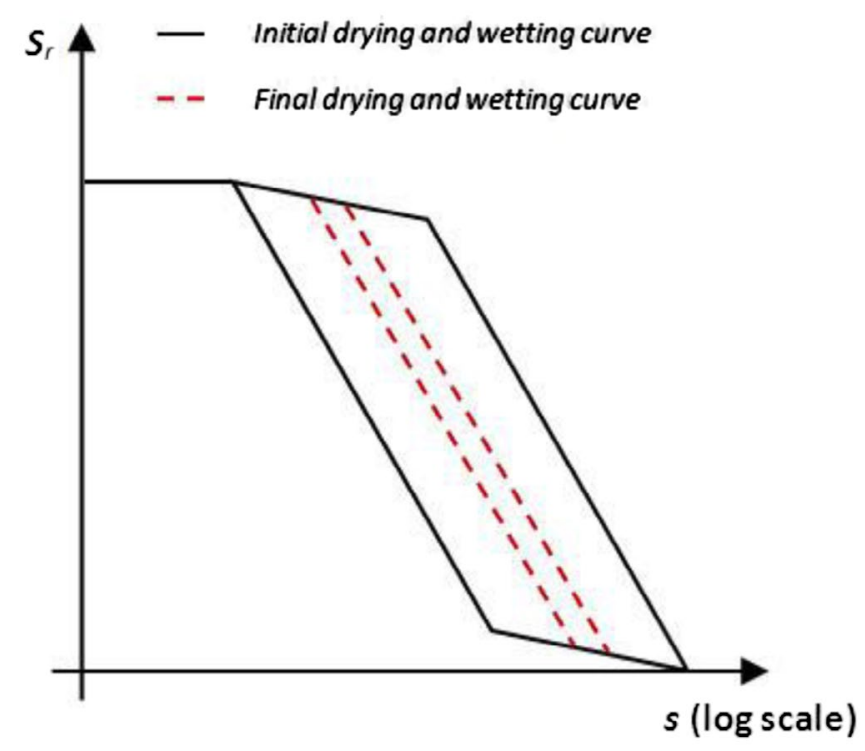

Figure 2. Evolution of the water retention curves with suction cycles.

$$
y_{\alpha}=h \cdot \varepsilon^{p}
$$

where $h$ is the kinematic hardening modulus.

To perform shakedown modelling, the proposed yield surface is presented in the transformed internal parameter $y_{a}$ as well as the preconsolidation stress $p$ plane (see Figure 3 ). In this (transformed internal parameter - preconsolidation stress) plane, the rectangular yield surface that characterises the behaviour of the expansive soil, translates between the minimum suction $s_{\min }$ position and the maximum suction $s_{\max }$ position during the wetting and drying cycles.

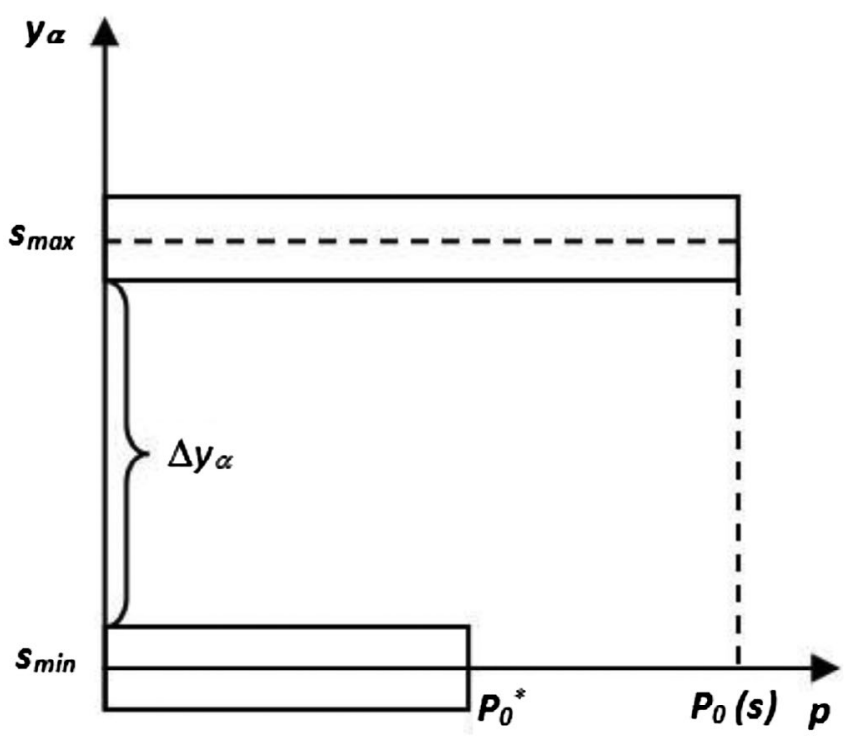

Figure 3. $y_{a-} p$ (transformed internal parameter-preconsolidation stress) plane for plastic shakedown 
Therefore, the variation of the volumetric plastic deformation $\Delta \varepsilon_{v s}^{p}$ during suction cycles can be computed by:

$$
\Delta \varepsilon_{v s}^{p}=\frac{1}{h} \cdot \Delta y_{\alpha}
$$

In this equation, $\Delta y_{\alpha}$ can be determined in the transformed internal parameter plane when the minimum suction and maximum suction are given.

\subsection{Elastic behaviour at the equilibrium state}

With the application of wetting and drying cycles, the equilibrium state can be obtained at the end of the suction cycles in the volumetric strain-suction plane in Figure 4, where no additional plastic strain accumulation can be observed. Because we have far too few experimental points at the equilibrium state, the hysteresis phenomenon cannot be described precisely. For now, the global test results on expansive soils during suction cycles present less point at the final equilibrium state. Consequently, a linear variation of the elastic strain with the suction is supposed at the equilibrium state, same as BExM model.

Here, the resilient modulus $E_{r}$ is defined and elastic strain at the equilibrium state is calculated by:

$$
\Delta \varepsilon_{v s}^{e}=\frac{1}{E_{r}} \cdot \Delta s
$$

where $E_{r}$ can be calibrated at the elastic equilibrium state. In the future, the more laboratory tests are carried out, the more precise hysteresis can be predicted.

\section{Parameter calibrations for the shakedown-based model}

For the proposed shakedown model of expansive soils, it requires the resilient modulus $\left(E_{r}\right)$, the kinematic hardening modulus $(h)$ and the threshold value of elastic limit for suction variation $\left(s_{a}\right)$. To

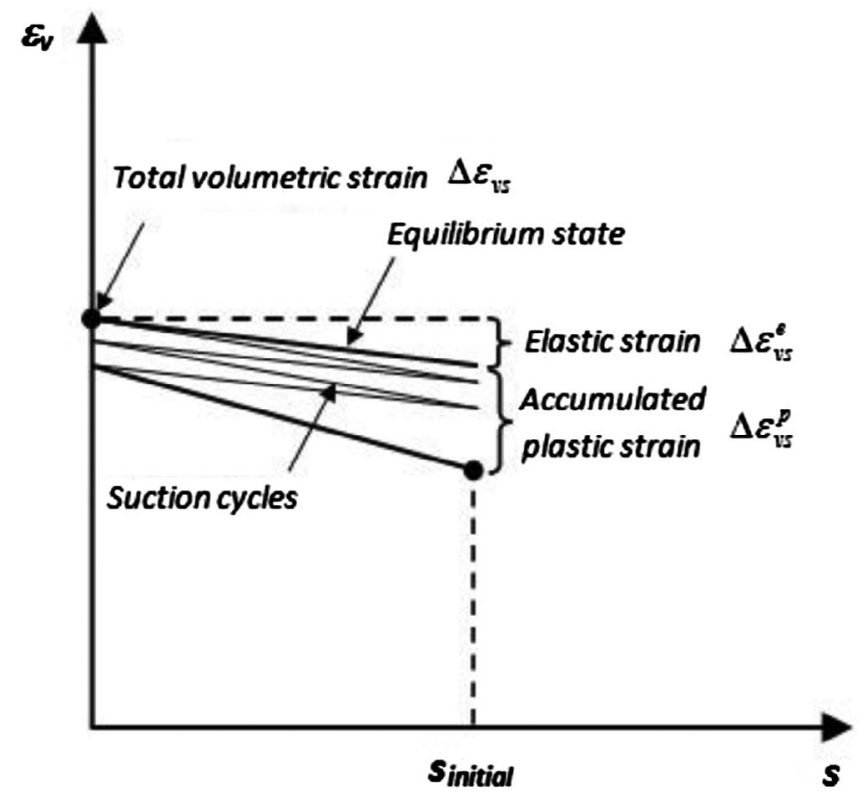

Figure 4. Variation of the volumetric strain during the suction cycles. 
determine these parameters, the cyclic suction-controlled odometer results of an expansive soil compacted at loose and dense initial states are firstly used. Then, the estimated parameters of the model are validated by comparing the model predictions with the experimental results obtained for the same expansive soil compacted at intermediate initial state.

\subsection{Test description}

Nowamooz and Masrouri $(2008,2010)$, Nowamooz and co-workers (2013) have performed a series of laboratory tests on an artificially prepared mixture of $40 \%$ silt and $60 \%$ bentonite. The main geotechnical properties of the materials and the mixture are shown in Table 1. The samples were compacted with an initial water content of 15\% under three vertical pressures: 1000, 2000 and $3000 \mathrm{kPa}$ and three dry densities were formed: $1.27,1.48$ and $1.55 \mathrm{Mg} \mathrm{m}^{-3}$, standing for loose, intermediate and dense samples, respectively. The initial suction of all compacted samples is considered to be $20 \mathrm{MPa}$. The suction-controlled odometer tests with suction cycles between 8 and $0 \mathrm{MPa}$ under three constant net mean stresses: 15, 30 and $60 \mathrm{kPa}$, have been carried out, which will be used to calibrate and validate the proposed shakedown model.

\subsection{Required parameters of shakedown-based model for loose and dense samples}

\subsubsection{Elasticity parameters}

The elasticity parameter $\left(E_{r}\right)$ can be estimated at the elastic equilibrium state of suction-controlled tests reached after several wetting and drying cycles. Tables 2 and 3 summarise the $E_{r}$ value of loose and dense samples for the different net mean stresses 15, 30 and $60 \mathrm{kPa}$. In Figure 5, we propose a linear variation of the inverse of the elasticity parameter $\left(1 / E_{r}\right)$ with the net mean stress $(p)$ :

$$
1 / E_{r}=A \cdot p+B
$$

where $A$ and $B$ are constant parameters related to the initial dry density of expansive soil given in Table 4 for the loose and dense samples.

Table 1. Soil properties studied by Nowamooz and Masrouri (2008, 2010 and Nowamooz et al., 2013).

\begin{tabular}{lccc}
\hline Soil & Liquid limit (\%) & Plasticity index (\%) & Specific gravity (Gs) \\
\hline Silt & 52 & 15 & 2.71 \\
Bentotnite & 111 & 30 & 2.63 \\
Mixture & 87 & 22 & 2.67 \\
\hline
\end{tabular}

Table 2. Required parameters of shakedown-based model for loose sample.

\begin{tabular}{lccc}
\hline Net mean stress $(\mathrm{kPa})$ & 15 & 30 & 60 \\
\hline$E_{r}(\mathrm{MPa})$ & 204 & 103 & 90 \\
$h(\mathrm{MPa})$ & 126 & 79 & 60 \\
$s_{a}(\mathrm{MPa})$ & Negligible & Negligible & Negligible \\
\hline
\end{tabular}

Table 3. Required parameters of shakedown-based model for dense sample.

\begin{tabular}{lccc}
\hline Net mean stress $(\mathrm{kPa})$ & 15 & 30 & 60 \\
\hline$E_{r}(\mathrm{MPa})$ & 53 & 55 & 51 \\
$h(\mathrm{MPa})$ & -125 & -163 & -540 \\
$s_{a}(\mathrm{MPa})$ & Negligible & Negligible & Negligible \\
\hline
\end{tabular}




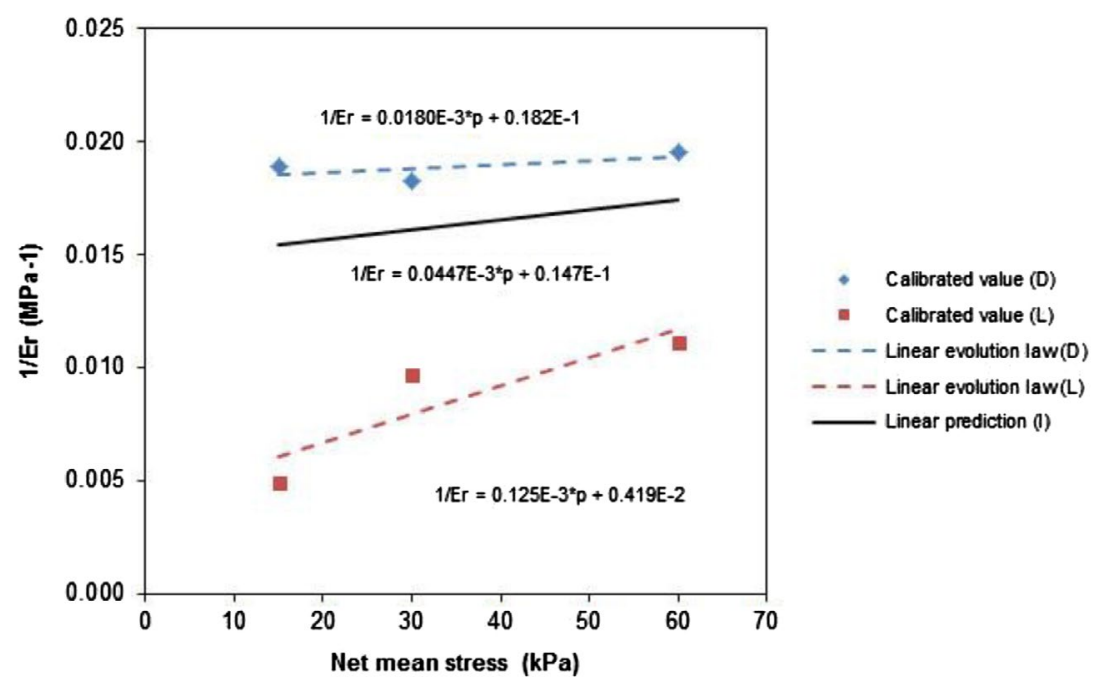

Figure 5. Variation of the inverse of the resillient modulus $\left(1 / E_{r}\right)$ with net mean stress for the loose and dense samples as well as the prediction of this parameter for the intermediate samples.

Table 4. Estimated parameters $A, B, C$ and $D$ for the loose and dense initial states.

\begin{tabular}{|c|c|c|c|c|}
\hline Parameters & $A\left(\mathrm{MPa}^{-2}\right)$ & $B\left(\mathrm{MPa}^{-1}\right)$ & $\mathrm{C}\left(\mathrm{MPa}^{-2}\right)$ & $D\left(\mathrm{MPa}^{-1}\right)$ \\
\hline Loose $\left(\gamma_{d}=1.27 \mathrm{Mg} \mathrm{m}^{-3}\right)$ & 0.125 & $0.419 \mathrm{E}-2$ & 0.188 & $0.589 \mathrm{E}-2$ \\
\hline Dense $\left(\gamma_{d}=1.55 \mathrm{Mg} \mathrm{m}^{-3}\right)$ & $0.180 \mathrm{E}-1$ & $0.182 \mathrm{E}-1$ & 0.138 & $-0.101 \mathrm{E}-1$ \\
\hline
\end{tabular}

\subsubsection{Plasticity parameters}

For the application of Zarka's shakedown theory on soil mechanics, the threshold value of elastic limit for suction variation $\left(s_{a}\right)$ may be considered very small and therefore it is neglected in this work (Tables 2 and 3$)$.

From the suction-controlled odometer tests, the hardening modulus $(h)$ can be deduced according to Equation (6), since know the accumulated plastic deformation $\left(\Delta \varepsilon_{v s}^{p}\right)$ as well as the transformed internal parameter $\left(\Delta y_{i j}\right)$ at a given net mean stress. Because of the volumetric shrinkage strains for the loose samples during the suction cycles, a positive sign was attributed to $h$ values. On the other hand, a negative sign was used for the dense samples because of the swelling strains. Tables 2 and 3 summarise these calibrated parameters of both samples. Figure 6 illustrates also the evolution of the inverse of the hardening modulus $(1 / h)$ with the net mean stress $(p)$. The larger the applied vertical pressure, the larger the inverse of the hardening modulus $(1 / h)$. In other words, the accumulated plastic deformation increases with an increase of the net mean stress. We propose additionally a linear variation of the inverse of the hardening modulus $(1 / h)$ with the net mean stress $(p)$ :

$$
1 / h=C \cdot p+D
$$

where $C$ and $D$ are constant parameters related to the initial dry density of expansive soils, given in Table 4 for the loose and dense samples. In contrast, this modulus is a constant for steels and it depends on the loading paths for unbound granular materials.

Figures 7 and 8 present the model results compared with the experimental results for the loose and dense samples at the net mean stresses of 15,30 and $60 \mathrm{kPa}$. It can be observed that the wetting and drying cycles generate the shrinkage strain accumulation for the loose samples and the swelling strain accumulation for the dense samples. It can be also noted that model estimations produce a good agreement with the test results at the different net mean stresses. 


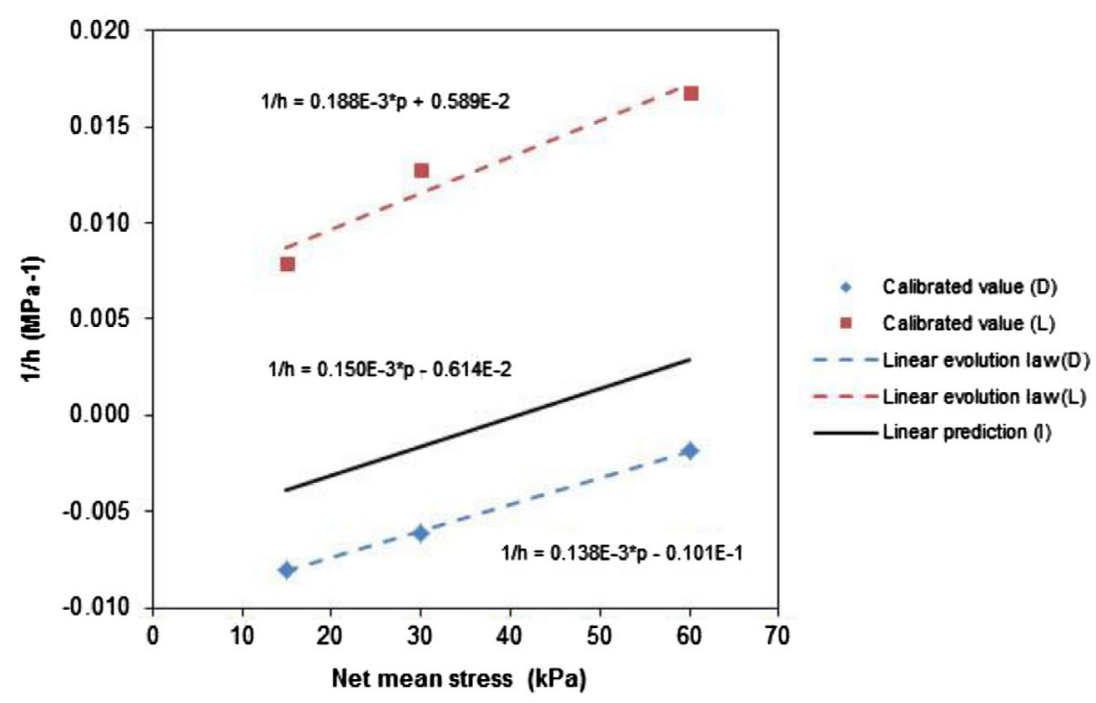

Figure 6. Variation of the inverse of the hardening modulus $(1 / h)$ with net mean stress for the loose and dense samples as well as the prediction of this parameter for the intermediate samples.

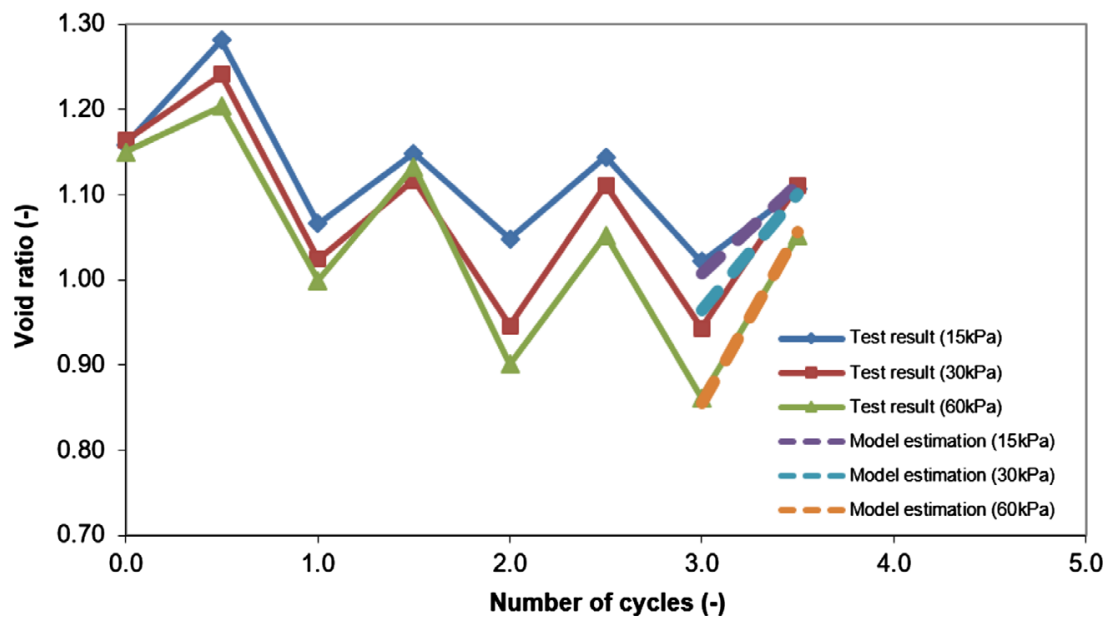

Figure 7. Comparison of results reported by Nowamooz and Masrouri (2008) with model estimations for the loose samples at different net mean stresses.

\subsubsection{Model validation for the intermediate sample}

The validation of the model is carried out with the test results obtained for the samples compacted at the intermediate initial state (Nowamooz et al., 2013). The linear variation of the inverse of the elasticity parameter $\left(1 / E_{r}\right)$ as well as the hardening modulus $(1 / h)$ with the net mean stresses is interpolated in Figures 5 and 6 for the these samples. The estimated parameters $A, B, C$ and $D$ of Equations (8) and (9) are presented in Table 5. For intermediate samples, the threshold value of elastic limit for suction variation $\left(s_{a}\right)$ is also considered negligible.

Based on these predicted model parameters, the model validation is conducted for the intermediated samples. Figure 9 represents the comparison between the test results and the model predictions at the different net mean stresses. For these samples, the initial state is closer to the reversible line which 


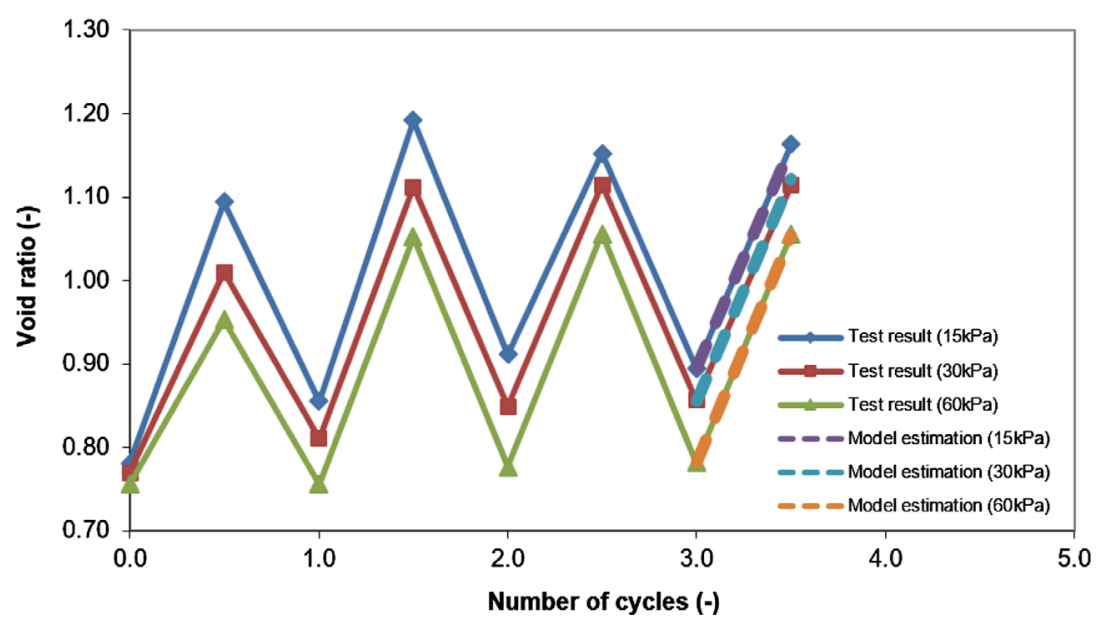

Figure 8. Comparison of results with model estimations for the dense samples at different net mean stresses.

Table 5. Estimated parameters $A, B, C$ and $D$ for the intermediate initial states.

\begin{tabular}{lcccc}
\hline Parameters & $A\left(\mathrm{MPa}^{-2}\right)$ & $B\left(\mathrm{MPa}^{-1}\right)$ & $C\left(\mathrm{MPa}^{-2}\right)$ & $D\left(\mathrm{MPa}^{-1}\right)$ \\
\hline Intermediate $\left(\gamma_{d}=1.55 \mathrm{Mg} \cdot \mathrm{m}^{-3}\right)$ & $0.447 \mathrm{E}-1$ & $0.147 \mathrm{E}-1$ & 0.150 & $-0.614 \mathrm{E}-2$ \\
\hline
\end{tabular}

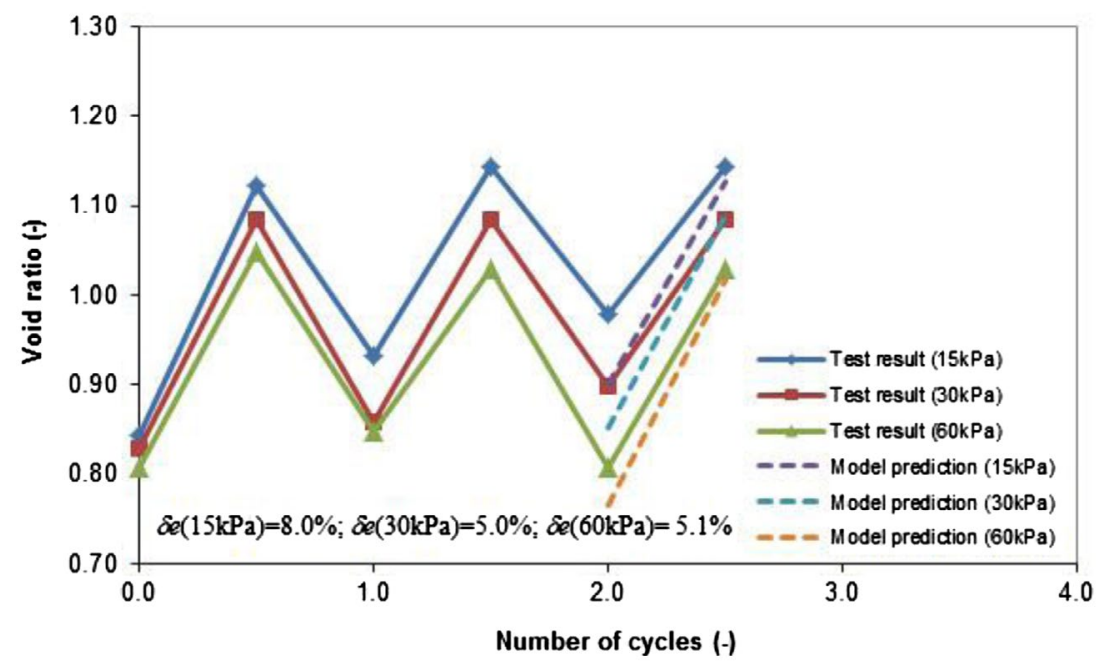

Figure 9. Comparisons of test results reported by Nowamooz et al. (2013) with model predictions for intermediate sample at the different net mean stresses.

need less suction cycles to obtain the equilibrium state. The relative tolerance varies between $5 \%$ and $8 \%$ confirming the capacity of the proposed model to estimate the accumulated plastic strains.

\section{Finite element modelling for the proposed shakedown model}

In this section, a structure of unsaturated expansive soils with an elasto-plastic behaviour is considered. Its boundary $\Gamma$ is subjected to the imposed surface forces $F_{i}(x)$ on $\Gamma_{F i}$ partition and the prescribed surface displacements $U_{j}(x)$ on $\Gamma_{U j}$ partition. The body force $X_{j}(x)$ and the initial strain $\varepsilon_{i j}^{\prime}(x, t=0)$ are defined in the 
volume $V$. Moreover, the wetting and drying cycles are also defined in the volume $V$ and these cycles are imposed between extremely dry and wet conditions.

\subsection{Mechanical analysis}

In this study, we suppose that the studied elasto-plastic structure meets the requirements of small displacements and small deformations.

In situ stress analysis is firstly performed before shakedown modelling of the structure subjected to wetting and drying cycles. Considering the finite element calculation with the imposed boundary conditions, the stress state can be solved by the linear elasticity:

$$
\sigma_{i j}^{*}(x, t)=D_{i j k l} \cdot\left[\varepsilon_{i j}^{*}(x, t)-\varepsilon_{i j}^{\prime}(x, 0)\right]
$$

in which $D_{i j k l}$ is the matrix of elastic moduli, $\sigma_{i j}^{*}(x, t)$ is the stress tensor and $\varepsilon_{i j}^{*}(x, t)$ is the strain tensor. Here, the superscript ${ }^{*}$ represents the parameters calculated from mechanical analysis. With this calculation, the net mean stress for each point in the structure can be determined, which will be used in the following shakedown modelling.

\subsection{Real response of suction variation}

For the suction variation in the volume of structure, the real response of the studied structure can be written as follows:

$$
\varepsilon_{i j}(x, t)=M_{i j k l} \cdot s_{k l}(x, t)+\varepsilon_{i j}^{p}(x, t)+\varepsilon_{i j}^{\prime}(x, 0)
$$

where $M_{i j k l}$ is the compliance elasticity matrix for suction loading, $\varepsilon_{i j}^{p}(x, t)$ is the plastic strain tensor and the strain tensor $\varepsilon_{i j}(x, t)$ is kinematically admissible with $U_{j}(x, t)$ on $\Gamma_{U j^{*}}$

In this equation, the suction tensor $s_{i j}(x, t)$ can be expressed by:

$$
s_{i j}=\left(u_{a}-u_{w}\right) \cdot \delta_{i j}=s \cdot \delta_{i j}
$$

where $\delta_{i j}$ is Kronecker delta whose value is 1 when $i=j$ and is equal to 0 otherwise.

\subsection{Elastic response of suction variation}

The response associated with the elastic part is expressed as follows:

$$
\varepsilon_{i j}^{e l}(x, t)=M_{i j k l} \cdot s_{k l}^{e l}(x, t)+\varepsilon_{i j}^{l}(x, 0)
$$

where $M_{i j k l}=\frac{1}{E} \cdot l_{i j k l} l_{i j k l}$ is the identity tensor, $l_{i j k l}=1$ if $i=j=k=l$ and the strain tensor $\varepsilon_{i j}^{e l}(x, t)$ is kinematically admissible with $U_{j}(x, t)$ on $\Gamma_{U j}$

Thus, the elasticity fields $U_{i}^{e l}(x, t)$ and $\varepsilon_{i j}^{e l}(x, t)$ can be calculated by an elastic analysis with the given boundary conditions and the compliance elasticity matrix for suction loading $M_{i j k l}$.

\subsection{Inelastic response of suction variation}

Because the general problem can be decomposed into elastic part and inelastic part, the inelastic strain can be expressed by the following equation:

$$
\varepsilon_{i j}^{i n e}(x, t)=\varepsilon_{i j}(x, t)-\varepsilon_{i j}^{e l}(x, t)
$$


where $\varepsilon_{i j}^{\text {ine }}(x, t)$ is kinematically admissible with 0 on $\Gamma_{U j}$.

Considering Equations (11) and (13), the above equation can be written as follows:

$$
\varepsilon_{i j}^{i n e}(x, t)=M_{i j k l} \cdot \rho_{k l}(x, t)+\varepsilon_{i j}^{p}(x, t)
$$

The residual field $\rho_{k l}(x, t)$ is obtained by the difference between total suction and elastic suction fields:

$$
\rho_{i j}(x, t)=s_{i j}(x, t)-s_{i j}^{e l}(x, t)
$$

where $\rho_{i j}(x, t)$ is statically admissible with 0 in $V$.

As long as the plastic strain tensor $\varepsilon_{i j}^{p}(x, t)$ and the compliance elasticity matrix for suction loading $M_{i j k l}$ are known, the inelastic problem can be solved with null boundary condition and consequently the inelastic fields $U_{i}^{i n e}(x, t)$ and $\varepsilon_{i j}^{i n e}(x, t)$ are obtained.

Eventually, the residual field can be derived from Equation (15) as follows:

$$
\rho_{i j}(x, t)=M_{i j k l}^{-1} \cdot\left[\varepsilon_{i j}^{i n e}(x, t)-\varepsilon_{i j}^{p}(x, t)\right]
$$

In the following section, this proposed method will be generalised to model the response of the fullscale structures.

\subsection{Structure with kinematic hardening}

The yield surface with a kinematic hardening can be defined by:

$$
f=\sqrt{\left(s_{i j}-y_{i j}\right) \cdot\left(s_{i j}-y_{i j}\right)}-s_{\alpha}
$$

where $s_{a}$ is the threshold value of elastic limit for suction variation and $y_{i j}$ is a kinematic hardening tensor which can be related to the plastic strain,

$$
y_{i j}=h \cdot \varepsilon_{i j}^{p}
$$

where $h$ is the kinematic hardening modulus, a critical important parameter in shakedown modelling.

By rewriting the Equation (16), the suction field can be expressed by:

$$
s_{i j}(x, t)=s_{i j}^{e l}(x, t)+\rho_{i j}(x, t)
$$

Here, the field of transformed structural parameters $Y_{i j}(x, t)$ is defined:

$$
Y_{i j}(x, t)=y_{i j}(x, t)-\rho_{i j}(x, t)
$$

Taking into account the above equations, the yield surface can be expressed by:

$$
f\left(s_{i j}^{e l}-Y_{i j}\right) \leq 0
$$

This equation indicates that the yield surface is centred in $s_{i j}^{e l}$ and translates in the transformed structural parameter $Y_{i j}$ plane.

With the transformed structural parameter field (Equations (15), (19) and (21)), the inelastic problem can be solved by:

$$
\varepsilon_{i j}^{i n e}(x, t)=M_{i j k l}^{\prime} \cdot \rho_{k l}(x, t)+\frac{1}{h} \cdot Y_{i j}(x, t)
$$


where $M_{i j k l}^{\prime}$ is the modified compliance elasticity matrix for suction loading, defined by the following equation:

$$
M_{i j k l}^{\prime}=M_{i j k l}+\frac{1}{h} \cdot l_{i j k l}
$$

where $I_{i j k l}$ is the identity tensor, $I_{i j k l}=1$ if $i=j=k=I$.

Considering Equation (23), the residual field of the elasto-plastic structure is obtained:

$$
\rho_{i j}(x, t)=M_{i j k l}^{\prime}{ }^{-1} \cdot\left[\varepsilon_{i j}^{i n e}(x, t)-\frac{1}{h} \cdot Y_{i j}(x, t)\right]
$$

Finally, the plastic strain field is given by combining Equations (19) and (21):

$$
\varepsilon_{i j}^{p}(x, t)=\frac{1}{h} \cdot\left[Y_{i j}(x, t)+\rho_{i j}(x, t)\right]
$$

Consequently, a one-to-one relation exists between the kinematic hardening variable field $y_{i j}(x, t)$ and the transformed structural parameter field $Y_{i j}(x, t)$. At any time $t$, for a given kinematic hardening variable field $y_{i j}(x, t)$, there is a unique residual field $\rho_{i j}(x, t)$, a unique suction field $s_{i j}(x, t)$ as well as a unique transformed structural parameter $Y_{i j}(x, t)$ and vice versa. Within this framework, the inelastic problem is solved through elastic analysis with a null boundary condition and a modified compliance elasticity matrix for suction loading. Eventually, all unknown fields at the limit state are obtained.

\subsection{Structure response under wetting and drying cycles}

During successive wetting and drying cycles (or suction cycles), the elastic suction field can be expressed by:

$$
s_{i j}^{e l}(x, t)=[1-\wedge(t)] \cdot s_{i j_{\min }}^{e l}(x)+\wedge(t) \cdot s_{i j_{\max }}^{e l}(x)
$$

where $s_{i j_{\min }}^{e l}(x)$ and $s_{i j_{\max }}^{e l}(x)$ are the minimal and maximal value of cyclic suction, respectively. $\wedge(t)$ is a monotonic periodic function, varied between 0 and 1 .

The local suction at the level of the plastic mechanisms is expressed as follows:

$$
\tilde{s}_{i j}(x, t)=s_{i j}(x, t)-y_{i j}(x, t)
$$

In the local suction plane, the plasticity convex domains $C_{0}$ is a fixed segment on the isoclinic suction axis. The normality law is written with the Moreau's notation (Moreau, 1971):

$$
\dot{\varepsilon}_{i j}^{p} \in \partial \phi_{C_{0}}\left(\tilde{s}_{i j}\right) \text { with } \tilde{s}_{i j} \in C_{0}
$$

$\partial \phi_{C_{0}}\left(\tilde{s}_{i j}\right)$ is the subdifferential to the convex $C_{0}$ at $\tilde{s}_{i j}$, where the plastic strain rate is an external normal to the convex $C_{0}$.

At the maximum suction state, the transformed structural parameter at the level of inelastic mechanism is expressed by:

$$
Y_{i j}=-\tilde{s}_{i j}+s_{i j_{\max }^{e}}^{e l}
$$

With

$$
Y_{i j} \in C\left(s_{i j \max }^{e l}\right) \text { and } C\left(s_{i j_{\max }}^{e l}\right)=\left(C_{0}\right)_{\min }+s_{i j_{\max }}^{e l}
$$

This equation implies that $Y_{i j}$ belongs to the convex $C\left(s_{i j \max }^{e l}\right)$ obtained from $\left(C_{0}\right)_{\min }$ with the translation $s_{i j \max }^{e l}$ (Figure 10). The normality law is 


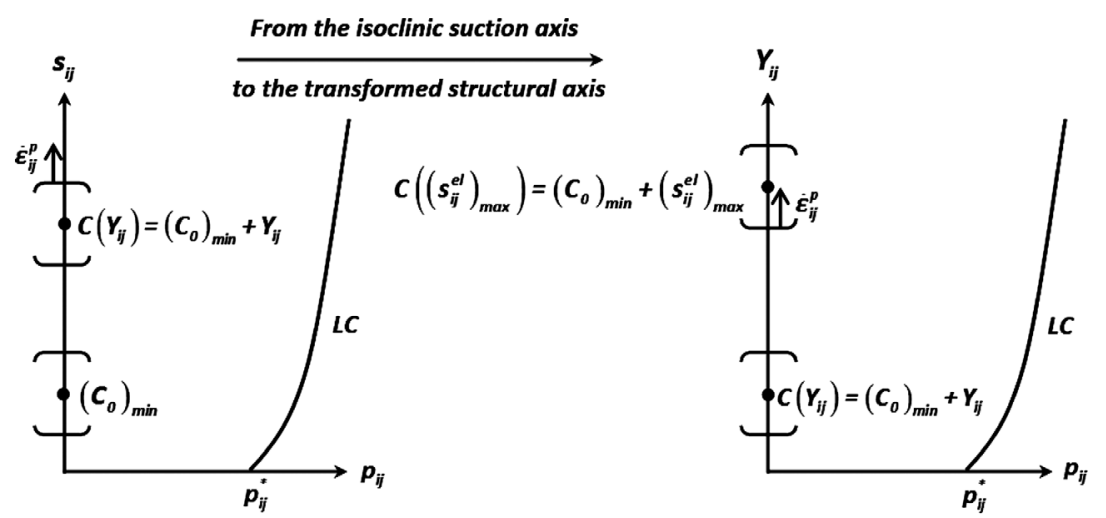

Figure 10. Evolution of plasticity convex along the plane of $\left(s_{i j}-p_{i j}\right)$ and the plane of $\left(Y_{i j}-p_{i j}\right)$.

$$
\dot{\varepsilon}_{i j}^{p} \in-\partial \phi_{C\left(s_{i j_{\max }}^{e l}\right)}\left(Y_{i j}\right) \text { with } Y_{i j} \in C\left(s_{i j_{\max }}^{e l}\right)
$$

$-\partial \phi_{C\left(s_{i i_{\max }}^{e l}\right)}\left(Y_{i j}\right)$ is the subdifferential to the convex $C\left(s_{i j \max }^{e l}\right)$ at $Y_{i j}(x, t)$, where the plastic strain rate is an internal normal to the convex $C\left(s_{i j \max }^{e l}\right)$. This convex is locally built for each plastic mechanism and the yield surface is a segment, centred in $s_{i j m a x}^{e l}$, translated in the transformed structural parameter plane.

A loading collapse (LC) yield surface is also presented in Figure 10, the same description presented in Section 2. It shows the increase of the preconsolidation stress $p_{i j}$ with the suction increase. In this study, no plastic deformation is generated by the mechanical loading during the wetting and drying cycles because the $p_{i j}$ value was selected less than $p_{i j}^{*}$ representing the preconsolidation stress at the saturated state (suction $=0$ ).

When the suction loading $\Delta s_{i j}^{e l}$ becomes very large, a stationary state can be reached and plastic shakedown is achieved presented in Figure 11. In this case, the distance between two extreme positions of the mobile convex centred in $s_{i j_{\min }}^{e l}$ and $s_{i j_{\max }}^{e l}$ in the transformed structural parameter plane can be obtained:

$$
\left\|\Delta Y_{i j}\right\|=\left\|s_{i j_{\max }}^{e l}\right\|-\left\|s_{i j_{\min }}^{e l}\right\|-2 \cdot s_{\alpha}
$$

Finally, the value of $\Delta Y_{i j}$ can be written as follows:

$$
\Delta Y_{i j}=\left(1-\frac{2 \cdot s_{\alpha}}{\left\|\Delta s_{i j}^{e l}\right\|}\right) \cdot \Delta s_{i j}^{e l}
$$

In these two equations, $\|\bullet\|$ is the notation of 2-norm.

\section{Numerical simulation of the in situ behaviour of an expansive soil}

In this section, the plastic strain field and inelastic displacements of an expansive soil will be simulated after several wetting and drying cycles due to the variation of the climatic conditions, till the stabilised limit state. We use the finite element code CAST3M (2015) in which the proposed shakedown-based model has been implemented.

Figure 12 shows the studied geometry $600 \mathrm{~cm} \times 200 \mathrm{~cm}$, made up of the intermediately compacted expansive soil (presented in Section 3). For the simulations, the geometry is discretised into four-node quadrilateral elements and 4800 elements have been used to analyse 2D plane strain problem. 


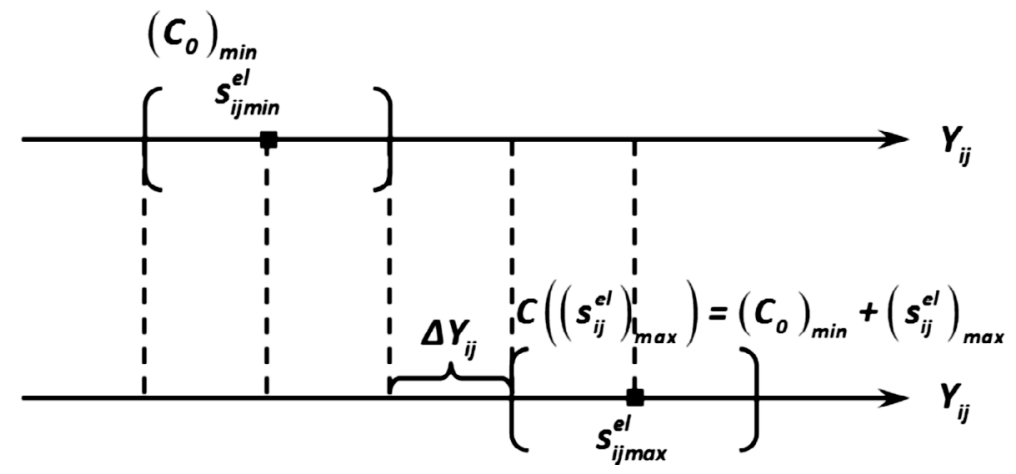

Figure 11. Transformed structural parameter plane for plastic shakedown.

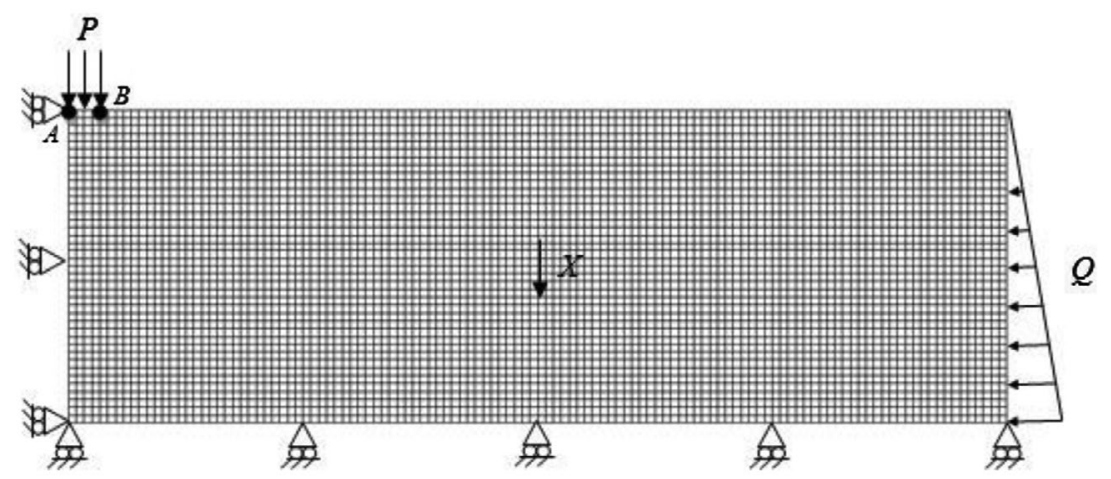

Figure 12. Finite element meshing and loading description for 2D geometry simulation.

Table 6. Mechanical parameters of the intermediate samples.

\begin{tabular}{lcccc}
\hline Parameters & $E(\mathrm{MPa})$ & $v(-)$ & $\gamma_{d}\left(\mathrm{Mg} \cdot \mathrm{m}^{-3}\right)$ & $K_{0}(-)$ \\
\hline Intermediate soil & 18 & 0.2 & 1.48 & 0.5 \\
\hline
\end{tabular}

Before shakedown calculation, the in-situ geostatic analysis of the expansive soils is performed where the gravity and lateral stresses are applied to the model (Figure 12). This geostatic stresses are determined by the initial dry density of soil $\left(\gamma_{d}\right)$ and the lateral stress coefficient $K_{0}$ where these values are summarised in Table 6.

Young modulus $E$ and Poisson ratio $v$ necessary for the elastic mechanical analysis are also given in Table 6.

Different vertical loads $P$ are applied on the top of the geometry between points $A$ and $B$ in Figure 12 (the length of $A B$ is $30 \mathrm{~cm}$ ): $15,30,60 \mathrm{kPa}$ and the limit stress of $67.85 \mathrm{kPa}$. The limit stress is $67.85 \mathrm{kPa}$ produces the maximum net mean stress of $60 \mathrm{kPa}$ in the finite element modelling. Since we obtained the evolution law of shakedown model between 15 and $60 \mathrm{kPa}$ for all the studied materials, the net mean stress values beyond $60 \mathrm{kPa}$ are not taken into account in the numerical modelling.

For a given vertical stress $P$, the resilient modulus $E_{r}$ as well as the hardening modulus $h$ can be estimated according to the Equations (8) and (9), where the parameters $A, B, C$ and $D$ are reported in Table 5.

We considered a linear variation of suction with depth as described in Figure 13 in the dry season, while the soil is fully saturated (suction zero) in the wet season. Then, the finite element calculation of the limit state is performed for the wetting and drying cycles between these two extreme conditions under different vertical loads. 


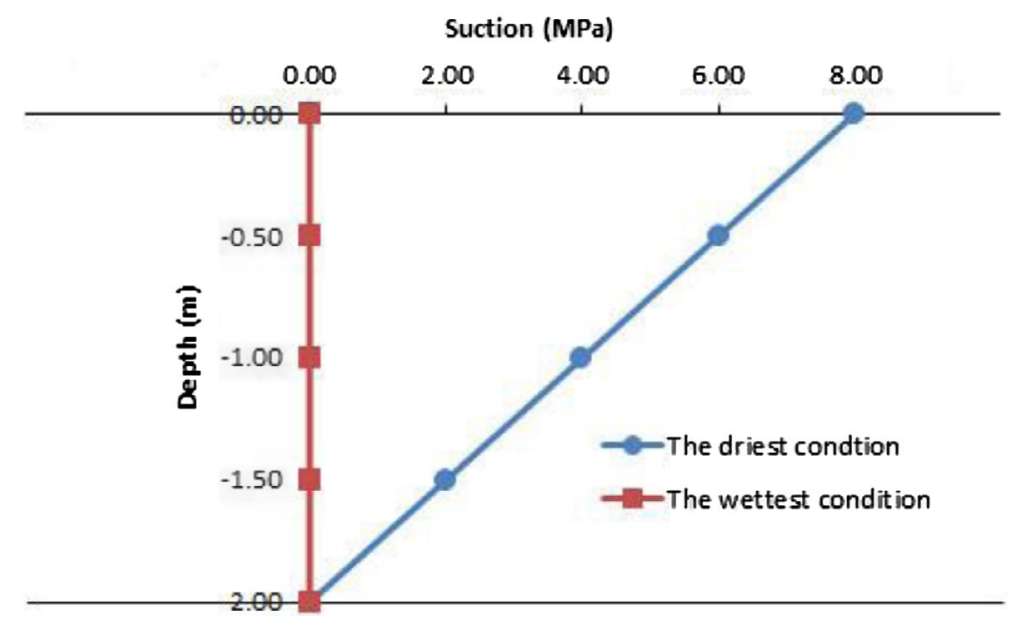

Figure 13. Suction profile at the driest and the wettest conditions for 2D geometry simulation.

(a)

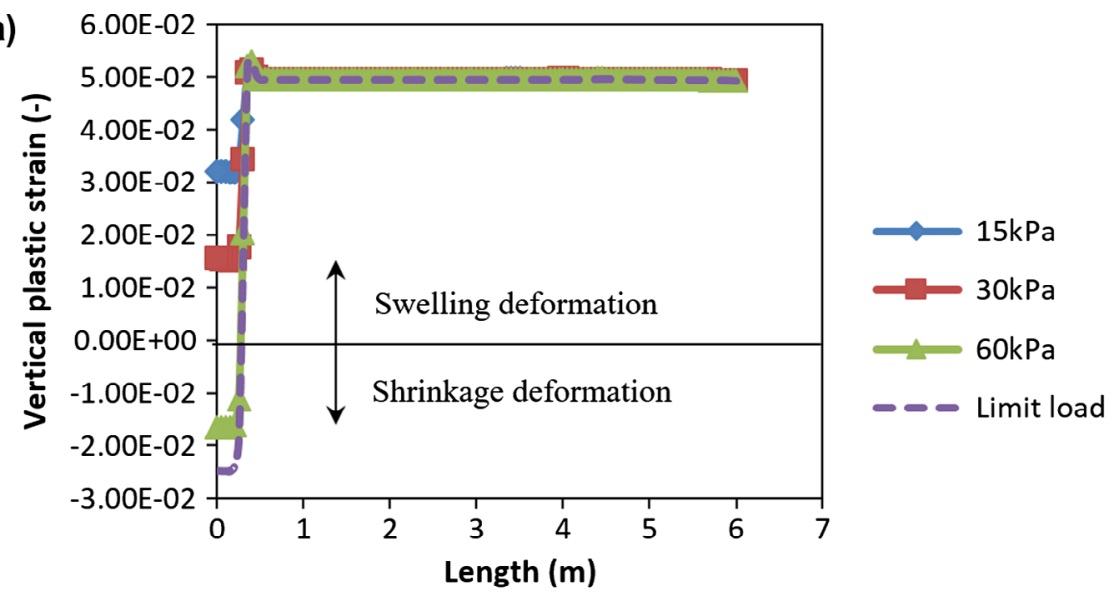

(b)

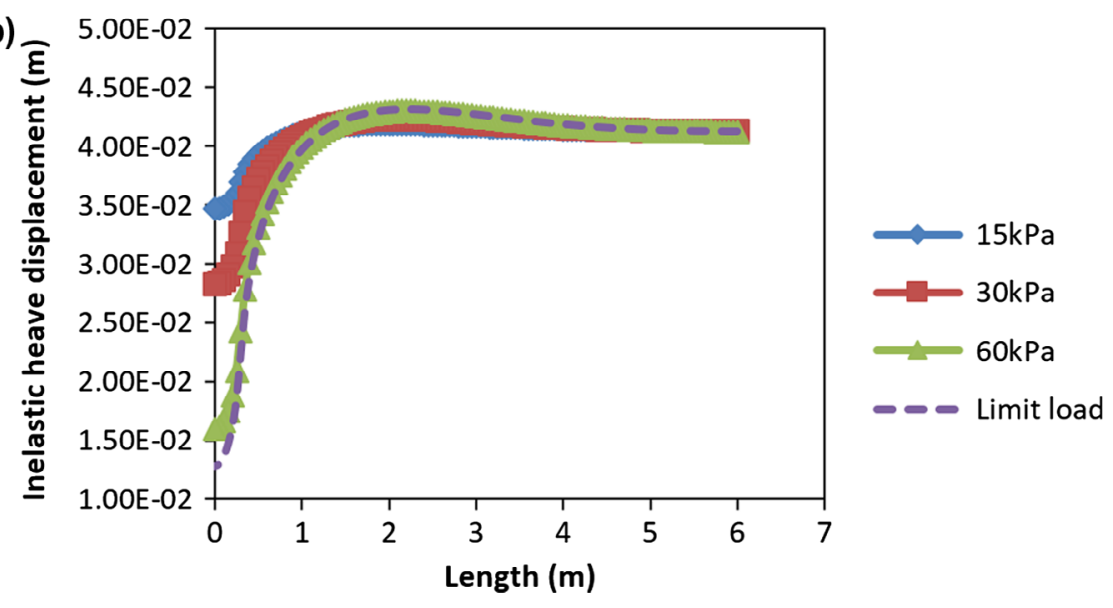

Figure 14. Finite element calculations on the surface $(y=0 \mathrm{~m}$ ) of 2D geometry: (a) plastic strain field; (b) inelastic displacement. 
Figure 14(a) shows the plastic strains on the soil surface $(y=0 \mathrm{~m})$ after several wetting and drying cycles for the different vertical stresses. It can be observed that the vertical stress mainly influences the plastic strain field between points $A$ and $B$. The swelling plastic strains are produced at the vertical stresses of 15 and $30 \mathrm{kPa}$, while the accumulated shrinkage deformations are occurred for the higher vertical stresses. Outside the loading area $A B$, the swelling plastic strain reaches its maximum because of null external loads.

Figure 14(b) presents the inelastic displacement field of the geometry surface $(y=0 \mathrm{~m})$ after wetting and drying cycles under the different vertical stresses. Between points $A$ and $B$, no settlement happens after the wetting and drying cycles and the heaving deformation decreases with the increase of the vertical overstress. All these findings can be related to the residual field in the studied geometry (see Equation(15)).

In general, external loads decide the stress distribution inside the structure and consequently influence the magnitude of heaving deformation. Therefore, light infrastructures are damaged seriously when the expansion occurred. To control the heaving deformation of expansive soils, necessary methods of treatment are suggested in the references (Ahmad, 1988; Lucian, 2011).

\section{Conclusions}

Several models are developed for the complex hydro-mechanical behaviour of the expansive soils submitted to the successive wetting and drying cycles, but these models are based on the traditional incremental method in elasto-plasticity leading to a very large calculation time. To solve this problem, the simplified model based on Zarka shakedown method is developed for unsaturated expansive soils.

The proposed shakedown model requires five parameters to be defined: parameters $A$ and $B$ for the linear evolution law of elasticity parameters $\left(1 / E_{r}\right)$ determined from the equilibrium state at the end of the wetting and drying cycles; parameters $C$ and $D$ for the linear evolution law of hardening modulus $(1 / h)$ calibrated from the accumulated plastic strains during the wetting and drying cycles; and the threshold value of elastic limit for suction variation $\left(s_{a}\right)$, taken zero for the sake of simplification.

With the framework of shakedown theory, finite element calculations of a 2D (plane strain) model, made up of intermediate soils was carried out. The soil is subjected to suction cycles between extremely dry and wet conditions under different vertical loads, till the stabilised limit state is achieved. The results show that the swelling plastic strains on the surface of the model $(y=0 \mathrm{~m})$, are produced at the lower vertical stresses, while the accumulated shrinkage deformations are occurred for the higher vertical stresses. Only inelastic heaving displacement can be observed within the $2 \mathrm{D}$ geometry after considering the residual field and we have also checked that the maximum vertical inelastic displacement depends on the vertical loads.

Our future development will deal with the activation of the LC yield surface with the suction cycles, same as BEXM model, to couple our proposed shakedown-based model with the subsequent mechanical behaviour of the expansive soils.

\section{Disclosure statement}

No potential conflict of interest was reported by the authors.

\section{Funding}

This work is financially supported by the project of Natural Science Foundation of Shandong [grant number ZR2016AB18] and the Program of China Scholarship Council [CSC N: 2011008046].

\section{References}

Ahmad, R. (1988). Engineering properties and mineralogical composition of expansive clays in al-qatif area (Thesis). University of Petroleum and Minerals Dhahran, Saudi Arabia. 
Al-Homoud, A. S., Basma, A. A., Malkawi, A. I. H., \& Bashabsheh, M. A. (1995). Cyclic swelling behavior of clays. Journal of Geotechnical Engineering, 121, 562-565.

Allou, F., Chazallon, C., \& Hornych, P. (2007). A numerical model for flexible pavements rut depth evolution with time. International Journal for Numerical and Analytical Methods in Geomechanics, 33, 1-22.

Alonso, E. E., Gens, A., \& Josa, A. (1990). A constitutive model for partially saturated soils. Geotechnique, 40, 405-430.

Alonso, E. E., Romero, E., Hoffmann, C., \& Escudero, E. G. (2005). Expansive bentonite/sand mixture in cyclic controlled suction drying and wetting. Engineering Geology, 81, 213-226.

Alonso, E. E., Vaunat, J., \& Gens, A. (1999). Modeling the mechanical behavior of expansive clays. Engineering Geology, 54, 173-183.

CAST3M (2015). CAST3M is a research FEM environment; Its development is sponsored by the French Atomic Energy Commission. Retrieved from http://www-cast3m.cea.fr/

Chazallon, C., Allou, F., Hornych, P., \& Mouhoubi, S. (2009). Finite element modeling of the long term behavior of a full scale flexible pavement with the shakedown theory. International Journal for Numerical and Analytical Methods in Geomechanics, 33, 45-70.

Chazallon, C., Koval, G., Hornych, P., Allou, F., \& Mouhoubi, S. (2009). Modeling of rutting of two flexible pavements with the shakedown theory and the finite element method. Computers and Geotechnics, 36, 798-809.

Cui, Y. J., Yahia-Aissa, M., \& Delage, P. (2002). A model for the volume change behavior of heavily compacted swelling clays. Engineering Geology, 64, 233-250.

Day, R. W. (1994). Swell-Shrink behavior of compacted clay. Journal of Geotechnical Engineering, 120, 618-623.

Dif, A. E., \& Blumel, W. F. (1991). Expansive soils under cyclic drying and wetting. Geotechnical Testing Journal, 14, 96-102.

Habiballah, T., \& Chazallon, C. (2005). An elastoplastic model based on the shakedown concept for flexible pavements unbound granular materials. International Journal for Numerical and Analytical Methods in Geomechanics, 29, 577-596.

Lucian, C. (2011). Geotechnical aspects of buildings on expansive soils in kibaha. Stockholm, Sweden: Royal Institute of Technology.

Moreau, J. J. (1971). Rafle par un convexe variable (Séminaire unilatérale). Montpellier: Université de Montpellier.

Nowamooz, H., Jahangir, E., \& Masrouri, F. (2013). Volume change behavior of a swelling soil compacted at different initial states. Engineering Geology, 153, 25-34.

Nowamooz, H., \& Masrouri, F. (2008). Hydromechanical behavior of an expansive bentonite/silt mixture in cyclic suctioncontrolled drying and wetting tests. Engineering Geology, 101, 154-164.

Nowamooz, H., \& Masrouri, F. (2010). Influence of suction cycles on the soil fabric of compacted swelling soil. Compted Rendus Geoscience, 342, 901-910.

Sharma R. S. (1998). Mechanical behavior of unsaturated highly expansive clays (Doctoral thesis). University of Oxford, Oxford.

Sharp, R., \& Booker, J. (1984). Shakedown of pavements under moving surface load. Journal of Transportation Engineering, $110,1-14$.

Sun, D. A., Sheng, D. C., Cui, H. B., \& Sloan, S. W. (2007). A density-dependent elastoplatic hydro-mechanical model for unsaturated compacted soils. International Journal for Numerical and Analytical Methods in Geomechanics, 31, 1257-1279.

Sun, W. J., \& Sun, D. A. (2012). Coupled modeling of hydro-mechanical behavior of unsaturated compacted expansive soils. International Journal for Numerical and Analytical Methods in Geomechanics, 36, 1002-1022.

Wheeler, S. J., Sharma, R. S., \& Buisson, M. S. R. (2003). Coupling of hydraulic hysteresis and stress-strain behavior in unsaturated soils. Géotechnique, 53, 41-54.

Zarka, J., \& Casier, J. (1979). Elastic plastic response of structure to cyclic loading: Practical rules. Mechanics Today, 6, $93-198$.

Zarka, J., Frelat, J., Inglebert, G., \& Kasmai-Navidi, P. (1990). A new approach in inelastic analysis of structures. Gif-sur-Yvette, France: CADLM. 